\title{
A two-step planning method to increase accessibility to medium complexity procedures for public secondary healthcare
}

\author{
Um método de planejamento em duas etapas para aumentar \\ a acessibilidade a procedimentos de média complexidade para \\ serviços de saúde pública em cuidados secundários
}

João Flávio de Freitas Almeida (https://orcid.org/0000-0002-3884-217X) ${ }^{1}$

Francisco Carlos Cardoso de Campos (https://orcid.org/0000-0003-2172-0181) ${ }^{2}$
${ }^{1}$ Departamento de Engenharia de Produção, Escola de Engenharia, Universidade Federal de Minas Gerais (UFMG). Av. Presidente Antônio Carlos 6627, Pampulha. 31270-901 Belo Horizonte MG Brasil. joao.flavio@dep.ufmg.br ${ }^{2}$ Núcleo de Estudos Em Saúde Coletiva, Escola de Medicina, UFMG. Belo Horizonte MG Brasil.

\begin{abstract}
The specialized care level of the public Brazilian national health system is critical and chronically underfunded. Few studies have evaluated public secondary care planning on a strategic level, so there are open issues yet to examine. This study aims at locating medical centers and sizing equipment based on a two-step optimization process to meet the population's needs. The models consider physicians' propensity for working on a metropolis and the patients' choice on moving the least from their municipalities, therefore, conflicting decisions. The models provide the location of medical centers, the assignment of equipment to such locations, and the additional hours of specialists required to meet official standards of demand. Available equipment with idle capacity should partly satisfy the requirement for exams within the current infrastructure. For the remaining uncovered demand, the second step of the optimization model suggests the acquisition of additional equipment for the elected medical centers to meet established needs. The proposed location of secondary care facilities covers $834 \mathrm{mu}$ nicipalities, corresponding to $97.77 \%$ of the estate, with an average patient displacement of $58.73 \mathrm{~km}$ (CI95\%: $56.18 \mathrm{~km}-61.28 \mathrm{~km}$ ). In general, 39 out of 77 health regions should hire additional hours of medical specialties. Pediatrics and gynecology represent the major gap.
\end{abstract}

Key words Public health planning, Secondary care, Location of medical centers
Resumo A atenção especializada do sistema público de saúde brasileiro é crítica e subfinanciada. Poucos estudos avaliaram o planejamento da atenção secundária em um nível estratégico, portanto ainda há questões em aberto a serem examinadas. Este estudo objetiva determinar a localização de centros médicos e a quantidade de equipamentos com base em um processo de otimização em duas etapas para atender a população. Balanceamos decisões conflitantes de propensão dos médicos em trabalharem em metrópoles e de pacientes em mudarem o mínimo de seus municípios para fornecer a localização dos centros médicos, e equipamentos a esses locais $e$ as horas adicionais de especialistas para atender aos padrões oficiais de demanda. Para a demanda restante, a segunda etapa do modelo de otimização sugere a aquisição de equipamento para os centros médicos eleitos, para atender às necessidades. A localização proposta das unidades de atendimento secundário abrange 834 municípios, correspondendo a $97,77 \%$ do estado, com um deslocamento médio de pacientes de 58,73 km (IC95\%: 56,18 $\mathrm{km}-61,28 \mathrm{~km}$ ). Em geral, 39 das 77 regióes de saúde devem contratar horas adicionais de especialidades médicas. Pediatria e ginecologia representam a maior lacuna.

Palavras-chave Planejamento da saúde pública, Cuidados secundários, Localização de centros médicos 


\section{Introduction}

The location of healthcare units in a hierarchical system is critical on setting the population access to health services, consequently, the size of health units, hospitals, and medical centers have been a topic of political and scientific relevance. In Brazil, the decreasing economic growth imposes challenges to the deployment of good public healthcare planning. While fast aging communities raise services demand and increase the health system's federal law ${ }^{1}$ establishes even tighter bounds on the public health budget. Consequently, leaders have strived on setting priorities in allocating resources. This study aims at recognizing and solving a location-allocation problem on public secondary care in Minas Gerais using mathematical programming models. Health needs are based on demographic projections ${ }^{2}$ and the Ministerial Decree ${ }^{3}$.

Since the 1988's Federal Constitution ${ }^{4}$, a national health system (Sistema Único de Saúde SUS) have established free healthcare at the primary, secondary and tertiary level to all Brazilian. The system follows principles of universalization, equity, and integrality ${ }^{5}$, where citizen should have access to primary, secondary and tertiary care in an integrated and decentralized health system ${ }^{6}$. Over the past years, SUS has amplified access to primary and tertiary care. The primary care is organized and decentralized including health promotion and diseases' prevention by low-cost events, reaching $74.76 \%$ of municipalities ${ }^{7}$ in December 2019. The tertiary care, which comprises high-costs procedures, is executed by county, public teaching hospitals and contracted private sectors providers, paid by the SUS at about market value. The secondary care consists of specialized services at the outpatient and hospital levels, with intermediate technological density between primary and tertiary care, where procedures of medium complexity are performed. The three services levels are interdependent ${ }^{8}$.

The provision of secondary care, however, is problematic. At the second level, healthcare has little regulation and SUS is highly reliant on the private sector, therefore, medium complexity procedures are often limited to individuals with private health plans. Less than one-fourth of Computed Tomography scanners and Magnetic Resonance Imaging scanners in Brazil are public ${ }^{5}$.

The healthcare location models are an extension of the classic p-median, p-centers ${ }^{9}$, set-covering ${ }^{10}$, and the max-covering model ${ }^{11}$, and the location-allocation model ${ }^{12}$. Such problems have been an active research area $^{13}$. The $\mathrm{p}$-centers and the location-allocation models are of particular importance to this work because, collectively, they address issues of equity, minimizing the distance between remote patients, and the equipment allocation to facilities.

For a historical insight, we refer the attracted readers to a comprehensive review ${ }^{14}$, efficacious case studies ${ }^{15}$ and recent surveys $s^{16,17}$. Applications embrace a 3-level location perinatal facilities ${ }^{18}$; a maximal covering location problem for health care planning adopting genetic algorithm ${ }^{19}$; the inclusion of physicians preferences for a primary care system facility location problem ${ }^{20}$; the integration of community based organizations with health care providers addressed by an hierarchical location model in a multi-objective framework $^{21}$; a developed support system to optimize the equipment allocation ${ }^{22}$; the tactical workforce capacity planning ${ }^{23}$; geographical accessibility by a p-median location model ${ }^{24}$ and a performance assessment of primary care health units ${ }^{25}$. Solutions also approach location-allocation by a twophase procedure ${ }^{26-28}$. Notwithstanding the vast literature, most studies address the primary care problem within a municipality geographic scope. Studies regarding location-allocation problems for secondary care are scarce, with few works addressing realistic problems ${ }^{17,20}$.

The study aims at proposing a method for secondary care services location-allocation by evaluating the primary and tertiary's system capabilities. In this labor-intensive service, workforce costs are nearly $70 \%$ of the total costs. Medical procedures are often performed in equipment. We elect the number of equipment per inhabitants according to official standards, presented on Ministerial Decree $1,631^{3}$. The following steps consists in describing the adopted method for health care planning problem on strategic level, and use it to discuss planning scenarios in a Brazilian state.

\section{Methods}

We study the healthcare planning at the state level of Minas Gerais, in which the planner must select secondary care facilities locations and designate equipment to them. The planner must combine patients and physician's preferences, adequately size workload, and assure service quality to justify the public infrastructure financing. Medical procedures are often accomplished on equipment; therefore, we evaluate this recourse 
considering Ministerial Decree $1,631^{3}$ health parameters of required number of equipment per thousand inhabitants. Finally, the planner must consider, simultaneously, (i) patients' multiple medical service needs, (ii) the available idle capacity of equipment on servers, and (iii) the rationally use of infrastructure in the context of a hierarchical health care system with limited resources availability.

Minas Gerais is the second most populous Brazilian state, with more than 20 million inhabitants, it is the most numerous in terms of municipalities and districts, 853 and 1,633, and it is the fourth biggest state, with $586.528 \mathrm{~km}^{2}$. The first medical center, in the proposed new arrangement, was established in $2016^{29}$. In this study, 51 medical centers would be installed providing 9 medical specialties. The selection of 116 candidate municipalities resulted from the contribution of experts in medicine, engineering, demography, and the government, representing patients and would ponder physicians' predilection and patient's choice of maximal displacement resulting in municipalities with over 30 thousand inhabitants offering at least three medical specialties services.

The purpose is twofold: (i) minimizing the weighted sum of distances between patients' demand, clustered on districts and physicians' service supply, located on municipalities, and (ii) minimizing the number of equipment to meet secondary care centers' need according to official criteria of equipment per inhabitants. Official parameters set specialists and medical equipment per inhabitants. The number of professionals is given in terms of specialists' available hours per micro healthcare region. Remark that there are numerous primary cares and tertiary care specialists and equipment in a hierarchical system, so we decrease the available capacity from the estimated demand set on Ministerial Decree 1,631 ${ }^{3}$. The records are provided by a history of outpatient and hospital production provided by Datasus Outpatient and Hospital Information System and Applications ${ }^{30,31}$. Further, the model should provide the additional hiring hours of specialties if the number of professionals per medical center is not capable of satisfying the local demand.

While a cost-based method has been approached $^{32}$, the main goal of this study is different, which is to minimize the displacement of patients to physicians, setting location medical specialties centers. Once patients and physicians' goal are satisfied, we optimize the allocation of equipment, therefore, equipment acquisition does not guide patients and physician's displacement. Therefore, we introduce a two-step process to solve this problem by mathematical optimization. On the first step, we analyze physicians' preferences for selecting several candidate municipalities with minimum infrastructure as municipalities with more than 30,000 inhabitants, since this is the number of inhabitants for municipality for installing small-sized hospitals; next, we develop a MILP model to elect medical centers facilities which minimize the weighted sum of demand and distances between patients and physicians of all specialties. The offer of medical specialties services is mainly provided by healthcare micro-regions. Each healthcare micro region represents a set of municipalities. Hub municipalities in micro-regions are separated within a range of 150 to 200 kilometers. If additional hours of medical specialties need to be hired due to the lack of physicians on such micro-region, we apply a penalty $\mathrm{AD} \sim \mathrm{U}[\mathrm{a}, \mathrm{b}]$ where $\mathrm{AD}$ follows a uniform distribution within the continuous interval $[a, b]$ for physicians' average displacement from different micro-regions to supply the lack of medical specialties.

For the second step, we propose a MILP model to meet the patient's requirement for exams on equipment. Before procuring new equipment for the chosen medical centers, the demand for exams on equipment is partly met by the available idle capacity of existing equipment in medical centers and hospitals. Following, new devices are allocated to the medical centers elected on the first step. The model minimizes the weighted sum of demand for exams and distances between patients and medical centers. The equipment allocation depends on demand parameters and the distance from elected medical centers, with new equipment, to patients. The equipment types do not share the same resources. They are independent of each other. This circumstance enables the adoption of one equipment allocation model for each type of equipment.

We represent a state with I districts and $\mathrm{J} \mathrm{mu}-$ nicipalities. A secondary care facility $j$ is located in a municipality $j$, therefore, the index $j$ refers to a single location as facility of a municipality. $\mathrm{K} \subset$ ( $\mathrm{I} \times \mathrm{J})$ are the accessible path between I and J. Patients move from local districts to municipalities to be assisted by E specialties. These specialties are distributed over $\mathrm{M}$ health care micro-regions. We consider $\mathrm{D}_{i j}$ as the distance between district $i$ and facility $j$, which is limited by $\mathrm{D}_{\max } . \mathrm{H}_{i e}$ is the demand of patients of district $i$ by medical specialties $e$. Due to budgeting constraints, the cen- 
tral planner limits number of secondary health care facilities by P. We consider the availability of physicians to set $A_{m e}$ as the service offer for each medical specialties $e$ form a micro health region $m$ for secondary care services. The additional binary parameters $\mathrm{R}_{j m}$ and $\mathrm{T}_{j}$, indicate if municipality $j$ is located on region $m$, and if municipality $j$ has infrastructure. Eventually, the physicians' displacement between micro regions may occur to satisfy the demand or additional hours of specialties should be temporarily hired with the private sector, therefore, a penalty $A D$ is applied. The model is developed to solve the following questions: (i) The demand of district $i$ is met by specialty $e$ on municipality $j$ (represented by the binary variable $x_{i e j}$ ) ?; (ii) Should a health care facility be located at municipality $j$ (represented by the binary variable $y_{j}$ )?; and (iii) How many additional hours of specialties $e$ should be hired for region $m$ (represented by the variable $\mathrm{w}_{m e}$ )? The MILP model of centers location is formulated as follows.

$$
\begin{aligned}
& \underset{m i n i m i z e}{\min } \sum_{i j \in k} \mid \mathrm{D}_{i j} \leq \mathrm{D}_{m a x} \Sigma_{e \in \mathrm{E}} \mathrm{D}_{i j} \mathrm{H}_{i e} x_{e i j} \\
& +\sum_{m \in M} \Sigma_{e \in \mathrm{E}} \mathrm{w}_{m e} \mathrm{AD}
\end{aligned}
$$

The objective function (1.0), minimizes the distances, limited by $\mathrm{D}_{\max }$ between patients, on districts and physician, on medical centers, and the additional hiring hours of medical specialties. Distance is weighted by patients demand and weighted by an average physicians' displacement from one micro region to the other to provide incentives for selecting districts close to each medical center. This function is subject to the following constraints:

$$
\left.\sum_{j \in J}\right|_{(i j) \in k} x_{e i j}=1 \quad \forall e \in E, i \in I
$$

On equation (1.1), the request for medical services of each district must be attended by only one medical center.

$$
\sum_{j \in J} \mid \mathrm{T}_{j}=1 \quad \mathrm{y}_{j}=\mathrm{P}
$$

In equation (1.2), the quantity of medical centers is set according to the planner financial-economic condition, that can change by planning strategy.

$$
x_{e i j} \leq y_{j} \quad \forall e \in E, i \in I, j \in J
$$

Constraint (1.3) set the circumstances for allocating specialties of districts to medical centers, which occurs only if a municipality is designated to receive a medical center.

$$
\begin{aligned}
& \sum_{(i j) \in k} \mid \mathrm{R}_{j m}=1 \mathrm{H}_{i e} x_{e i j} \leq A_{m e}+\mathrm{w}_{m e} \\
& \forall e \in E, m \in M
\end{aligned}
$$

Constraint (1.4) establishes that the demand for each medical service of municipalities that belongs to a health care region is limited by the available workforce of each medical specialties for each health care region. If demand exceeds the accessible capacity, additional hours of specialists should be required from another micro-region or should be hired from private sector, for instance. Constraints (1.5)-(1.7) set the domain of the decision variables:

$$
\begin{array}{ll}
\mathrm{y}_{j} \in\{0,1\} & \forall j \in J \\
x_{e i j} \in\{0,1\} & \forall e \in E, i \in I, j \in J \\
\mathrm{w}_{m e} \geq 0 & \forall e \in E, m \in M
\end{array}
$$

For the equipment allocation model used in the second step of the two-step optimization process we consider the demand $H_{i}$ for image exams that exceeds the available equipment capacity $K_{i}$. Distances between municipalities $i$ and $j$ are presented by $D_{i j}$ and limited by $D_{\max }$, while $P$ is the purchase limit of additional equipment. A facility overall efficiency $E_{i}$ on municipality $i$ is considered. Equipment, with nominal capacity $W$, may be acquired to medical centers, therefore, we adopt a binary parameter $C_{i}$ to select the municipality $i$ that received a Medical Center on the previous model. Each municipality $i$ has $B_{i}$ inhabitants. We also include empirical parameters $F_{i j}$ and $A$ representing the historical flow of patients from municipalities $i$ to $j$, and a percentage of destiny population for evaluating patients' flow, respectively. However, such parameters can be adjusted for scenarios evaluation. Parameter $T$ is a penalty for displacement over maximum distance and avoid the model infeasible solutions, therefore, it is also a parameter for scenario evaluation. The proposed second-stage model should help answering the following questions: (i) Is the demand of municipality $i$ met by equipment of municipality $j$ (represented by binary variable $\alpha_{i j}$ )?; (ii) How many equipment should be acquired for municipality $j$ (represented by variable $\beta_{j}$ )?; and (iii) How many patients may have to move over the maximum distance from a municipality (represented by variable $r_{i}$ )? We adopt a simplifying assumption that image exams are converted in the time of equipment use. The MILP model is presented as follows:

$\operatorname{minimize} \sum_{(i j) \in I}\left(D_{i j} H_{i} \frac{\alpha_{i j}}{1+F_{i j}}+\left(\frac{r_{i} T}{1+F_{i j}}\right) H_{i}\right)$ 
The objective function, on equation (2.0), minimizes the number of patients' exams on equipment, considering the displacement from patients' districts to medical centers. The flows of patients can be influenced by the historical flow. In case of moving beyond the maximum distance, a penalty is applied. This function is subject to constraints (2.1)-(2.10):

$$
\sum_{j \in I} \alpha_{i j}=1 \quad \forall i \in I
$$

On equation (2.1), the demand for examinations of each municipality must be attended by only one medical center of a municipality or attended the same municipality $i$.

$$
\sum_{i \in I} H_{i} \alpha_{i j} \leq K_{j} E_{j} H_{i}+\beta_{J} C_{j} W \quad \forall j \in I
$$

On constraint (2.2), the demand for exams is met by available idle capacity or by the allocation of new equipment on the medical centers selected on the first step of the optimization process.

$$
\sum_{j \in I}\left(K_{j} E_{j}+\beta_{J} C_{j} W\right) \geq \sum_{i \in I} H_{j}
$$

Constraints (2.3) guarantee that the overall capacity, provided by available capacity and new equipment, is greater than the demand for exams of all municipalities.

$$
\sum_{j \in I} \beta_{J} \leq P
$$

Constraint (2.4) limits the amount of equipment acquisition according to economic circumstances.

$$
\sum_{i \in I} \alpha_{i j} \geq 1 \quad \forall j \in I \vee K_{j}>0 \mid C_{j}>0
$$

On constraint (2.5) the demand for exams is met preferably to the municipality with idle equipment capacity by a new medical center.

$$
\mathrm{B}_{i} \alpha_{i j} \geq \mathrm{AB}_{i} \alpha_{i j} \quad \forall j \in I, j \in I \vee \mathrm{D}_{i j}<\mathrm{D}_{\max }
$$

Constraint (2.6) denotes a historical move of patients to municipalities with a bigger population. Although this is not a mandatory rule in practice, it was suggested by decision makers to avoid unusual policies and facilitate an initial discussion.

$$
\mathrm{D}_{i j} \alpha_{i j}-\mathrm{r}_{i} \leq \mathrm{D}_{\max } \quad \forall j \in I, j \in I
$$

Constraints (2.7) relax the condition of maximum distance and penalize this situation on the objective function.

$$
\begin{aligned}
& \beta j \in Z+\forall j \in I \\
& \alpha_{i j} \in\{0,1\} \quad \forall i \in I, j \in I \\
& r_{i} \in Z+\forall i \in I
\end{aligned}
$$

Constraints (2.8)-(2.10) set the domain of the decision variables. The results of the proposed method are presented in section 4 . The inclusion of parameters $\mathrm{F}_{\mathrm{iji}}, A$, and $T$ was suggested by decision makers to facilitate an initial discussion. Of course, parameters $\mathrm{F}_{\mathrm{ij}}$, and $A$ can be set to zero, and parameter $T$ can be set to one in order to evaluate the optimal mathematical solution.

\section{Results}

The optimization set municipalities listed in Chart 1 . Our facility location model presents a configuration considering accessibility to facilities over the state, therefore, to compare the results with the current situation in the state, we highlight the actual medical centers that should have its capacity expanded. The selected medical centers are spread over the geographic state area since the optimization set geographic balance locations of medical centers considering maximal displacement from patients on districts to medical centers on municipalities. Following, additional optimization would be run to allocate medical equipment to each unit. The models' parameters were sourced from IBGE $^{33}$, DATASUS ${ }^{31}$ and Ministerial Decree ${ }^{3}$. The maps were generated in Tabwin ${ }^{34}$. The MILP models were implemented in MathProg $\left(\mathrm{GLPK}^{35}\right)$ in a Linux Mint 17.3 64-bit, RAM of $8 \mathrm{~GB}$, Intel Core I5 $2.50 \mathrm{GHz}$ $\mathrm{x} 2$ processor. The first mathematical programming model comprises 342,624 constraints and 327,202 variables, all of which are binary. The second mathematical programming model comprises 337,200 constraints and 896,627 variables, with 46,504 integers from which 45,650 are binary. Instances of each model reached an optimality gap of $2 \%$ within two hours.

The analysis revealed that the proposed location strategy can provide the coverage to $834 \mathrm{mu}-$ nicipalities $(97.77 \%)$. For this solution, the average patient displacement is $58.73 \mathrm{~km}$, residing in the interval $56.18 \mathrm{~km}$ and $61.28 \mathrm{~km}$ for $95 \%$ statistic confidence. The standard deviation is 37.50 $\mathrm{km}$. The shortest distance between two medical centers is $19 \mathrm{~km}$, while the longest distance between two medical centers is $230 \mathrm{~km}$. While 25 hours of mastologist supply the municipality of 
Chart 1. Municipalities selected to receive or expand ${ }^{\star}$ a medical center.

\begin{tabular}{|c|c|c|c|c|c|c|c|}
\hline Item & Municipality & Item & Municipality & Item & Municipality & Item & Municipality \\
\hline 1 & Alfenas ${ }^{*}$ & 14 & Curvelo & 27 & Lavras & 40 & Sabara \\
\hline 2 & Almenara & 15 & Diamantina $^{\star}$ & 28 & Leopoldina* & 41 & Santo Antonio do Monte \\
\hline 3 & Aracuai & 16 & Divinopolis & 29 & Manhuacu $^{\star}$ & 42 & Sao Joao del Rei ${ }^{\star}$ \\
\hline 4 & Araxa & 17 & Frutal $^{\star}$ & 30 & Montes Claros & 43 & Sao Lourenco \\
\hline 5 & Barbacena & 18 & G. Valadares* & 31 & Muriae $^{*}$ & 44 & Sete Lagoas* \\
\hline 6 & B. Horizonte ${ }^{\star}$ & 19 & Ipatinga & 32 & Paracatu & 45 & Taiobeiras $^{*}$ \\
\hline 7 & Betim & 20 & Itabira $^{*}$ & 33 & Passos $^{*}$ & 46 & Teofilo Otoni* \\
\hline 8 & B. de Minas* & 21 & Itabirito $^{*}$ & 34 & Patos de Minas & 47 & Uberaba \\
\hline 9 & Campo Belo* & 22 & Ituiutaba $^{*}$ & 35 & Patrocinio ${ }^{\star}$ & 48 & Uberlandia* \\
\hline 10 & Capelinha* & 23 & Janauba $^{*}$ & 36 & Pirapora* & 49 & Unai \\
\hline 11 & Caratinga $^{*}$ & 24 & Januaria $^{*}$ & 37 & Pocos de Caldas & 50 & Varginha \\
\hline 12 & C. Lafaiete & 25 & Jequitinhonha $^{*}$ & 38 & Pouso Alegre & 51 & Vicosa \\
\hline 13 & Contagem & 26 & Juiz de Fora* & 39 & Ribeirao das Neves ${ }^{\star}$ & & \\
\hline
\end{tabular}

Source: Elaborated by the authors.

Frutal, the highest number of hours of medical specialty resides in the capital, Belo Horizonte, with 11,792 hours of pediatric service. The model also set the minimum number of additional hours to be hired to meet the official standards for each medical specialty. In general, 39 out of 77 health regions should hire additional hours of medical specialties. Pediatrics and gynecology represent the major gap of 27 thousand hours on average, while urology, cardiology, nephrology, ophthalmology, angiology, endocrinology, and mastology require about one thousand additional hours per week to be hired for each medical specialty for MG.

The selection of medical centers considers all 853 municipalities and 1,633 districts of MG. These locations are arranged in 77 micro health regions that establish the availability of professionals. Consequently, the gap of each medical specialty is calculated for each micro health region considering both, the demand of 1,633 districts and the assignment of specialists to the 51 medical centers. The major lack of medical specialties hours resides in the north and in the midwest region of the state.

We evaluate scenarios by changing input parameters concerning patients, physicians, and government. For patients, we change the number of new medical centers in case the user migrates at most $100 \mathrm{~km}$ to $200 \mathrm{~km}$, for example. For physicians, we modify criteria of minimum infrastructure, varying the candidate municipalities' population from 30 to 60 thousand inhabitants. On the government plane, we create scenarios altering the number of medical centers, from 10 to 80 . The state government has recently faced a serious financial crisis ${ }^{36}$, and much of the health resource has been used for working capital expenditures rather than investments ${ }^{37}$. For this reason, we propose a range of scenarios with a low, medium and high amount of investment in this sector. Figure 1 presents the results.

The following step concerns in allocating equipment to the selected medical centers. The Decree $1,631^{3}$ sets official parameters for each type of equipment. According to the document, an MRI scanner can perform 5,000 exams per year. Demand estimates consist of 30 exams/1,000 inhabitants per year. Mammographs can perform 6.758 exams per year. The demand for this type of equipment is estimated as a percentage of women between 40 and 59 years. CT scanners, which are used on different body parts, and can perform 7,000 exams per year. Demand estimates consist of 2,307 exams/100,000 inhabitants. Conventional ultrasounds and Doppler ultrasounds can perform 3,024 exams per year. A demand of 150 exams/1,000 inhabitants is estimated per year for conventional ultrasound, while for Doppler ultrasound it is estimated $15 \%$ of this value, equivalent to high-risk pregnant women. The model can be used for each type of equipment. For the sake of didactics, we present the graphical analysis of the MRI and CT scanners, however, the evaluation for additional types of equipment is similar. Optimization results revealed that MRI scanners idle capacity could fulfill almost three-quarter of the demand. The purchase of an additional 20 MRI scanners, 10 CT scanners, 1 Mammograph, 330 Ultrasound, and 5 Doppler 
Ultrasound for new medical centers would cover the exams' demand for a maximum displacement of $200 \mathrm{~km}$. Such results are acceptable since the state presents large areas with low demographic density. Figures 2 and 3 shows the percentage of demand satisfaction by changing the maximum displacement and the number of new MRI and CT scanners.

A system was developed to provide flexibility and automate the optimization process. The first

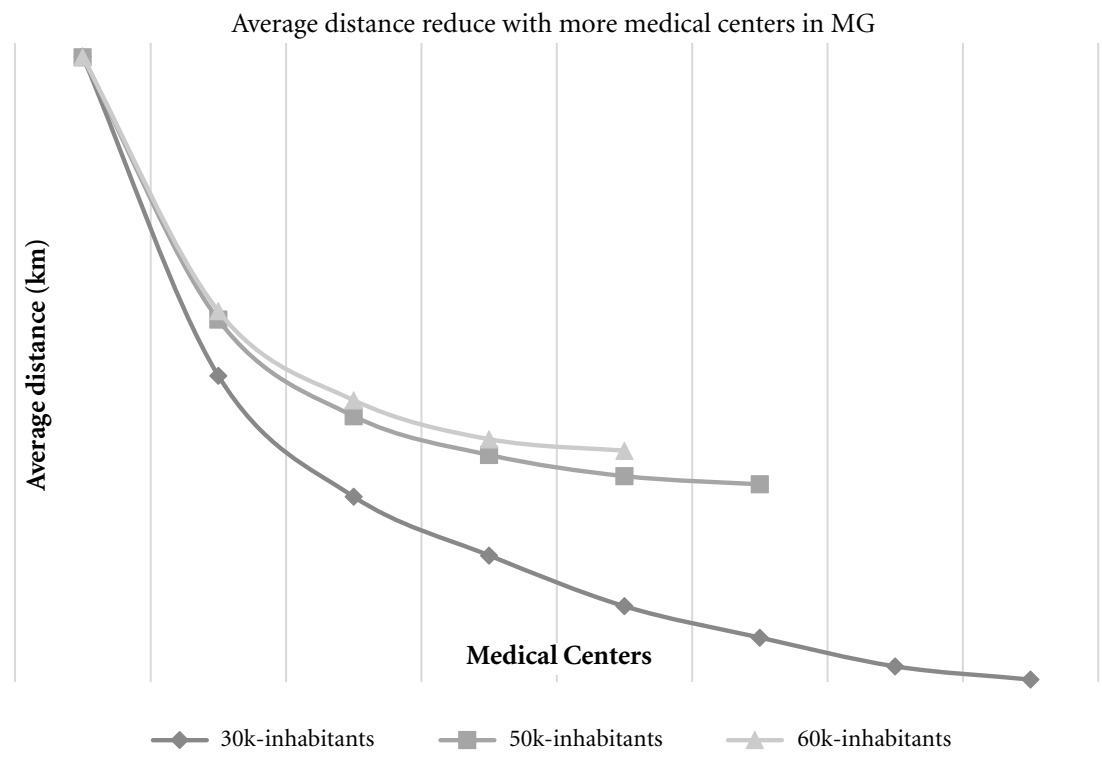

Figure 1. The average distance traveled by patients decreases considerably from $135 \mathrm{~km}$ to approximately $80 \mathrm{~km}$ with the investment on at least 40 new Medical Centers.

Source: Elaborated by the authors.

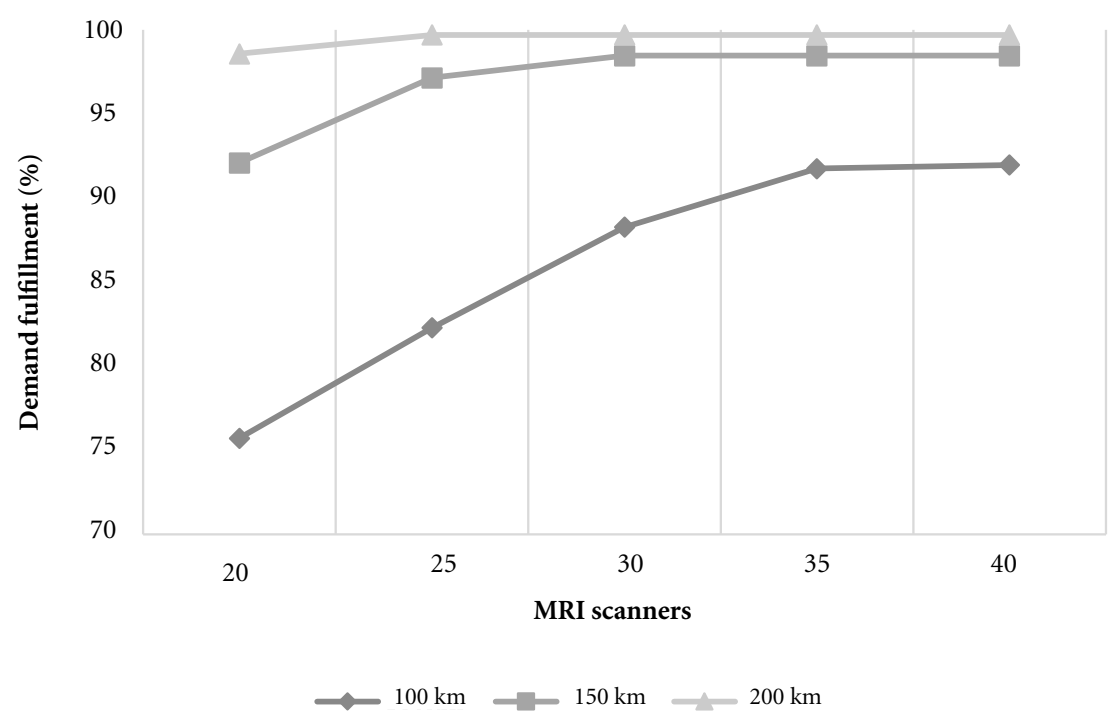

Figure 2. The percentage of demand fulfillment for MRI scanner changes with at distances of 100, 150 and 200 $\mathrm{km}$.

Source: Elaborated by the authors. 


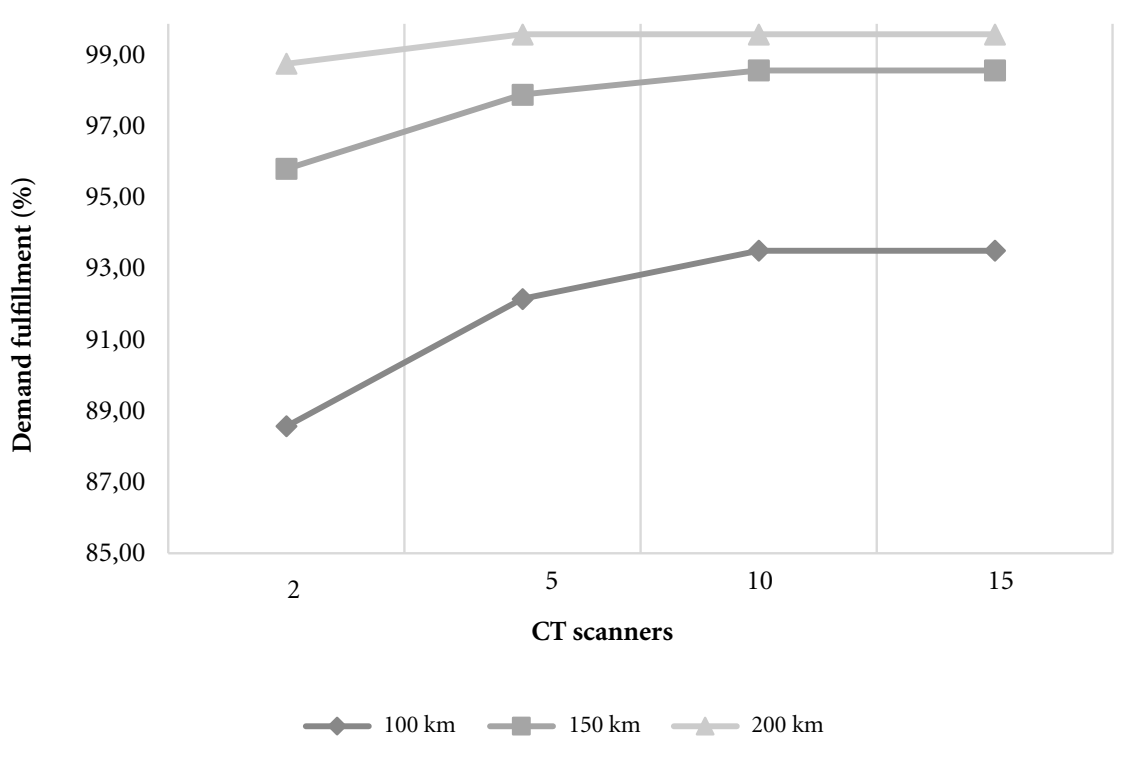

Figure 3. The percentage of demand fulfillment for CT scanners changes with at distances of 100, 150 and 200 $\mathrm{km}$.

Source: Elaborated by the authors.

step consists in providing the location of medical centers, the size of medical specialties teams, and allocate patients' demand, on districts to medical centers on municipalities. Following, a data analysis process is conducted to assign part of patients' demand for exams to the available idle capacity of existing health care infrastructure. The optimization model proposes the location and acquisition of new equipment to meet the remaining demand within a maximum distance. The system enables scenario analyses by varying the number of new equipment and a maximum distance of coverage.

The need for efficient resource allocation in the public health care network ${ }^{38}$ of MG is evident. Important constraints of supply of specialized services within the SUS have exacerbated the dependence of the system on purchasing secondary care services from the private sector. However, the accessibility of health care on the secondary level can be reached combining the rational use of the infrastructure with the appropriate selection of medical centers location and equipment allocation. Equipment costs vary from approximately 20, 100, and 200 thousand dollars for ultrasounds, CT scanners, and MRI scanners, respectively. After allocating part of the demand to idle capacity on municipalities, the acquisition of 333 ultrasound scanners, and 5 Doppler scanners, one mammography, 10 CT scanners, and 20 MRI scanners would fulfill most of the demand for exams on these types of equipment, as presented in Chart 2.

The results can directly contribute to health care planning by supporting knowledge-based policymaking and providing scenario analyses. Furthermore, it provides the integration and interaction of the decision makers into a solution procedure. The proposed method follows flexibility principles ${ }^{39}$, and represents an unstudied component of real health care location-allocation problems ${ }^{40}$. The two-step process proposed accessibility by locating medical centers based on specialties service needs and allocating equipment to the medical centers based on the uncovered demand for official planning criteria.

\section{Conclusion}

Recently, the low accessibility to medium complexity procedures has been pointed out by specialists as one of SUS bottlenecks ${ }^{41}$. In line with the system' requirements, this study proposed a 
Chart 2. Percentage of demand fulfillment for a suggested amount of equipment within the distances.

\begin{tabular}{|l|r|c|c|c|}
\hline \multicolumn{1}{|c|}{ Equipment } & \multicolumn{1}{c|}{ \# } & $\mathbf{1 0 0} \mathbf{~ k m}$ & $\mathbf{1 5 0} \mathbf{k m}$ & $\mathbf{2 0 0} \mathbf{~ k m}$ \\
\hline MRI Scanners & 20 & $75.71 \%$ & $92.08 \%$ & $98.57 \%$ \\
\hline CT scanners & 10 & $93.57 \%$ & $98.67 \%$ & $99.70 \%$ \\
\hline Mammograph & 1 & $96.85 \%$ & $99.26 \%$ & $99.94 \%$ \\
\hline Ultrasound & 333 & $96.75 \%$ & $97.11 \%$ & $100.0 \%$ \\
\hline Doppler Ultras. & 5 & $96.98 \%$ & $99.38 \%$ & $99.76 \%$ \\
\hline
\end{tabular}

Source: Elaborated by the authors.

two-step optimization method for setting out the location of medical centers and the equipment allocation for secondary care taking into account the tradeoff between patients' desire for minimum displacement, and physicians' preference for working on developed municipalities on the state of Minas Gerais. The proposed method considers the primary and tertiary's system capabilities. The bibliographic examination presented classical formulations enabling the selection of models' constraints similar to the studied problem. However, the literature showed a lack of location-allocation studies considering the context of the hierarchical health care system, the motivation of this study. Although the method was implemented in a case study for the state of Minas Gerais, it was recognized that the setting was of a generic character, representing an unstudied component of real health care location-allocation problems.

The first model found the optimal location of medical centers according to the demand for services of medical specialties and provided the required additional hours of specialists. The centers are dispersed over the state area and located in municipalities that meet minimum infrastructure requirements. Municipalities that do not host secondary care services are assigned to the selected municipalities as a reference for the region. The attribution strategy generated by the model is aligned with the Intermunicipal Health Consortiums and provided for in the Organic Law of the $\mathrm{SUS}^{42}$ in order to guarantee integral care to the population of the associated municipalities. A second model establishes the allocation of equipment to the medical centers. Demand for exams is assigned a priori to equipment with idle capacity on the current hierarchical infrastructure, as medical centers or hospitals. For the remaining uncovered demand, it is proposed the acquisition of the minimum amount of equip- ment for the medical centers to meet official standards. The expansion of 28 existing medical care facilities and the installation of new 23 of secondary care facilities in the proposed location is what is necessary to cover 834 municipalities (97.77\% of the estate) with an average patient displacement of $58.73 \mathrm{~km}$ (CI95\%: $56.18 \mathrm{~km}$ $61.28 \mathrm{~km}$ ). States not covered by this approach should have a special attention with customized solution from the state government. In general, 39 out of 77 health regions should hire additional hours of medical specialties. Pediatrics and gynecology represent the major gap.

In general, the findings suggested that the proposed two-step optimization process is a potential method to promote the interaction and integration of public health, medicine, and engineering teams, strengthening the decision-making process. The web system developed is a potential tool to support knowledge-based policymaking. It is important to highlight those mathematical models do not replace managers. On the contrary, it contributes to management decisions by providing the integration and interaction of the decision makers into a solution procedure by evaluating scenarios. The results need to be scrutinized by managers, who are expected to have a deeper understanding of the system results in a broader context of healthcare. The findings also contribute to recent debates about the use of analytic tools for health care system integration in the legal and regulatory landscape.

Some limitations of the study are worth mentioning. First, accurate overall efficiency levels of the current infrastructure are not effectively available on databases. Second, we did not explicitly consider indexes for physician's preference for municipalities with infrastructure, nor government preferences for municipalities including social vulnerability into the mathematical model. Such an analysis would have provided answers to questions of political aspects. Although geostatistical modeling is not within the scope of the work, the current deterministic method adopted can be further improved with the inclusion of stochastic variables for geostatistical modeling ${ }^{43}$, besides, gain in efficiency can contribute to reduce equity gaps without the need to redesign all healthcare systema ${ }^{44}$. Finally, despite the data simplification with deterministic values of official standards and databases parameters, the large-scale model still provides a detailed level of information for health care planning on the state level. Accordingly, the approach adopted in this work is suitable but will be overstrained if sto- 
chastic data and probabilistic scenarios are considered simultaneously, which is desirable.

For future related works, it is recommended (i) extending the formulation to model the primary and the tertiary care in an integrated health network (ii) expanding the model from a state boundary to the entire country, considering inter-state existing flows (iii) improving the quality of medical specialties offer parameters, adopting kernel density estimation ${ }^{45}$ based on historical observations, and (iv) including accessibility ${ }^{46}$ parameters on the model objective function.

\section{Collaborations}

JFF Almeida worked on models' design, analysis and final text. FCC Campos worked on the research and methodology. 


\section{References}

1. Emenda Constitucional no 95, de 15 de dezembro de 2016. Altera o Ato das Disposições Constitucionais Transitórias, para instituir o Novo Regime Fiscal, e dá outras providências. Diário Oficial da União 2016; 15 dez.

2. Instituto Brasileiro de Geografia e Estatística (IBGE). Projeção da População [Internet]. [cited 2019 May 5]. Available from: https://www.ibge.gov.br/apps/populacao/projecao/.

3. Portaria no 1.631 , de $1^{\circ}$ de outubro de 2015. Aprova critérios e parâmetros para o planejamento e programação de ações e serviços de saúde no âmbito do SUS. Diário Oficial da União; 2015.

4. Brasil. Constituição da República Federativa do Brasil de 1988. Diário Oficial da União 1988; 5 out.

5. Paim J, Travassos C, Almeida C, Bahia L, Macinko J. The Brazilian health system: history, advances, and challenges. Lancet 2011; 377(9779):1778-1797.

6. Brasil. Ministério da Saúde (MS). Unified Health System (SUS): structure, principles and how it works [Internet] [cited 2019 May 18]. Available from: http:// portalms.saude.gov.br/sistema-unico-de-saude.

7. Brasil. Ministério da Saúde (MS). Unified Health System. e-Gestor Atenção Básica [Internet]. [cited 2019 Dec 18]. Available from: https://egestorab.saude.gov. br/paginas/acessoPublico/relatorios/relHistoricoCoberturaAB.xhtml.

8. Macedo LM, Sueli TFM. Interdependência entre os níveis de atenção do Sistema Único de Saúde (SUS): significado de integralidade apresentado por trabalhadores da Atenção Primária. Interface (Botucatu) 2014; 18:647-660.

9. Hakimi SL. Optimum locations of switching centers and the absolute centers and medians of a graph. Operations $\operatorname{Res} 1964 ; 12(3): 450-459$.

10. Toregas C, Swain R, ReVelle C, Bergman L. The location of emergency service facilities. Operations Res 1971; 19:6.

11. Church R, ReVelle C. The maximal covering location problem. Papers Regional Sci 1974; 32(1):101-118.

12. Schilling D, Elzinga DJ, Cohon J, Church R, ReVelle C. The TEAM/FLEET models for simultaneous facility and equipment siting. Transportation Sci 1979; 13(2):163-175.

13. Rais A, Viana A. Operations research in healthcare: a survey. Int Transactions Operational Res 2011; 18(1):131.

14. Hale TS, Moberg CR. Location science research: a review. Ann Operations Res 2003; 123(1):21-35.

15. Brandeau ML. Creating impact with operations research in health: making room for practice in academia. Health Care Manag Sci 2016; 19(4): 305-312.

16. Farahani RZ, Hekmatfar M, Fahimnia B, Kazemzadeh N. Hierarchical facility location problem: Models, classifications, techniques, and applications. Computers Industrial Engineering 2014; 68(1):104-117.

17. Ahmadi-Javid A, Seyedi P, Syam SS. A survey of healthcare facility location. Computers Operations Res 2017; 79:223-263.

18. Galvao RD, Espejo LGA, Boey B. A hierarchical mode for the location of perinatal facilities in the municipality of Rio de Janeiro. Eur J Operational Res 2002; 138(3):495-517.
19. Shari SR, Moin NH, Omar M. Location allocation modeling for healthcare facility planning in Malaysia. Computers Industrial Engineering 2012; 62(4):10001010 .

20. Gunes ED, Yaman H, Ekyay BC, Verter V. Matching patient and physician preferences in designing a primary care facility network. J Operational Res Soc 2014; 65(4):483-496.

21. Khodaparasti S, Maleki H, Jahedi S, Bruni M, Beraldi P. Enhancing community-based health programs in Iran: a multi-objective location-allocation model. $\mathrm{He}$ alth Care Manag Sci 2017; 20(4):485-499.

22. Treurnicht MJ, Van Dyk L. A decision support system for equipment allocation in a telemedicine referral network. South African J Industrial Engineering 2014; 25(1):29-38

23. Van der Veen E, Hans EW, Veltman B, Berrevoets LM, Berden HJ. A case study of cost-efficient staffing under annualized hours. Health Care Manag Sci 2015; 18(3):279-288

24. Cirino S, Gonçalves LA, Gonçalves MB, Cursi ES, Coelho AS. Avaliação de acessibilidade geográfica em sistemas de saúde hierarquizados usando o modelo de p-medianas: aplicação em Santa Catarina, Brasil. Cad Saude Publica 2016; 32(4):e00172614.

25. Novignon J. Improving primary health care facility performance in Ghana: efficiency analysis and scal space implications. BMC Health Services Res 2017; 17(1):399.

26. Stummer C, Doerner K, Focke A, Heidenberger K Determining location and size of medical departments in a hospital network: A multiobjective decision support approach. Health Care Manag Sci 2004; 7(1):63-71.

27. Gu W, Wang X, McGregor SE. Optimization of preventive health care facility locations. Int J Health Geogr 2010; 9:17.

28. Luo J, Tian L, Luo L, Yi H, Wang F. Two-Step Optimization for Spatial Accessibility Improvement: A Case Study of Health Care Planning in Rural China. Biomed Res Int 2017; 2094654.

29. Estado de Minas. Primeiro Centro de Especialidades Médicas de Minas é inaugurado em Pirapora [Internet]. [cited 2017 Sep 28] Available from: https://www. em.com.br/app/noticia/gerais/2016/04/12/interna_ gerais,752198/primeiro-centro-de-especialidadesmedicas-de-minas-e-inaugurado-em-pir.shtml.

30. Departamento de Informática do SUS (DATASUS). Cadastro Nacional de Estabelecimento de Saúde [Internet]. [cited 2018 Sep 10]. Available from: http://cnes. datasus.gov.br/.

31. Departamento de Informática do SUS (DATASUS). Sistemas e Aplicativos do SUS [Internet]: [cited 2018 Sep 10]. Available from: http://datasus.saude.gov.br/ sistemas-e-aplicativos.

32. Almeida JFF, Pinto LR, Conceição SV, Campos FCCD. Medical centers location and specialists' allocation: a healthcare planning case study. Production 2019; 29:e20190006.

33. Instituto Brasileiro de Geografia e Estatística (IBGE). Censo Demográfico 2010 [Internet]. [cited 2018 Sep 10]. Available from: https://www.ibge.gov.br/estatisticas-novoportal/sociais/populacao/9662-censodemogra_co-2010.html. 
34. Departamento de Informática do SUS (DATASUS). Tabwin [Internet]. [cited 2019 Jun 11]. Available from: www.datasus.gov.br/tabwin.

35. Makhorin A. GNU linear programming kit: reference manual [Internet]. Moscow: Department for Applied Informatics, Moscow Aviation Institute; 2003. [cited 2019 Jun 11]. Available from: http://www. gnu. org/ software/glpk/glpk. html.

36. Agência Minas. Nota de esclarecimento [Internet]. [cited 2019 May 24]. Available from: http://www.agenciaminas.mg.gov.br/noticia/nota-de-esclarecimento-2019-02-22-14-50-00-0300.

37. Assembleia Legislativa de Minas Gerais. Relatório comprova baixo investimento na saúde em Minas [Internet]. 2018 [cited 2019 May 18]. Available from: https://www.almg.gov.br/acompanhe/noticias/arquivos/2018/07/11_audiencia_saude_relatorio_SUS. html.

38. Güneş ED, Melo T, Nickel S. Location problems in healthcare. In: Location science. Berlin: Springer, Cham.; 2019. p. 657-686.

39. De Neufville R, Scholtes S. Flexibility in engineering design. Cambridge: MIT Press; 2011.

40. Almeida JFF, Pinto LR, Conceição SV, Campos FCC, Júnior GM. A two-step optimization process for medical centers location and capacity allocation. In: Leiras A, González-Calderón CA, Brito Junior, I, Villa S, Yoshizaki HT. Operations Management for Social Good - 2018 POMS International Conference in Rio, RJ, Bra$z i l$. Rio de Janeiro: Springer; 2018. p. 107-117.

41. Folha de São Paulo. Apesar de problemas, SUS é referência em saúde pública, dizem especialistas [Internet]. 2018 [cited 2018 Apr 23]. Available from: https:// www1.folha.uol.com.br/seminariosfolha/2018/04/ apesar-de-problemas-sus-e-referencia-em-saude-publica-dizem-especialistas.shtml.

42. Brasil. Lei 8.080, de 19 de setembro de 1990. Dispõe sobre as condições para a promoção, proteção e recuperação da saúde, a organização e o funcionamento dos serviços correspondentes e dá outras providências. Diário Oficial da União 1990; 20 set.
43. Chaix B, Merlo J, Chauvin P. Comparison of a spatial approach with the multilevel approach for investigating place effects on health: the example of healthcare utilisation in France. J Epidemiol Community Health 2005; 59(6):517-526.

44. Wong KL, Brady OJ, Campbell OMR, Jarvis CI, Pembe A, Gomez GB, Benova L. Current realities versus theoretical optima: quantifying efficiency and sociospatial equity of travel time to hospitals in low-income and middle-income countries. BMJ Glob Health 2019; 4(4):e001552.

45. Botev ZI, Grotowski JF, Kroese DP. Kernel density estimation via diffusion. Ann Statistics 2010; 38(5):29162957.

46. Cirino S, Gonçalves LA, Gonçalves MB, Cursi ES, Coelho AS. Avaliação de acessibilidade geográfica em sistemas de saúde hierarquizados usando o modelo de p-medianas: aplicação em Santa Catarina, Brasil. Cad Saude Publica 2016; 32:e00172614.

Article submitted 26/02/2020

Approved 27/07/2020

Final version submitted 29/07/2020

Chief editors: Romeu Gomes, Antônio Augusto Moura da Silva 